\title{
Interactive comment on "The On-Orbit Performance of the Orbiting Carbon Observatory-2 (OCO-2) Instrument and its Radiometrically Calibrated Products" by David Crisp et al.
}

Anonymous Referee \#3

Received and published: 30 October 2016

This paper describes a latest performance of the OCO-2 radiance data products. The paper is well written and the topic is suitable for AMT. I recommend it to be published after the following comments are addressed.

p.2 I.30: The order of the operating temperatures in the parentheses is reversed.

p.13 I.17 : According to Table 3, a single bad sample is added on "1" July 2015 in the "WCO2" channel.

p.15 I.10 : The "V"7 cloud screening

p.16 I.24 : According to Table 4 and Figure 12, there are "3" discontinuities in the WCO2 
p.18 I.32 : (Figure "17")

p.24 I.7 : Haring et al. 2002 is not referred in the text.

AMTD

p.29 Figure 4 : It is better to unify the temperature unit in ${ }^{\circ} \mathrm{C}$.

p.44 I.2 : 755 (blue) and $771 \mathrm{~nm}$ "(red)"

Interactive

comment

Interactive comment on Atmos. Meas. Tech. Discuss., doi:10.5194/amt-2016-281, 2016. 